\title{
The Potentials of Whatsapp Group in Promoting Learning, Social Interaction and Democracy among Undergraduate Students in University of Maiduguri, Borno State Nigeria
}

Ebireri Omovigho Rani (Ph.D)*, Tijjani Kalli (Ph.D) and Sakir Aishatu (Ph.D)

\section{Department of Continuing Education and Extension Services, Faculty of Education, University of Maiduguri, Nigeria}

\section{*Corresponding Author:}

Email: omorae2001@ unimaid.edu.ng, omorae2001@ yahoo.com

\begin{abstract}
The Whatsapp platform created in the year 2009 is a mobile messaging app which allows the users to exchange messages without having to pay for SMS. It also makes communication and the distribution of multimedia messaging more easily and faster using internet connectivity. This study therefore investigated the potentials of Whatsapp group in promoting learning, social interaction and democracy among undergraduate students in University of Maiduguri, Borno State Nigeria. The study had three objectives and three corresponding research questions. Qualitative design was adopted for the study. The population consisted of all the four Whatsapp groups formed for the undergraduate levels of adult education programme. Out of these four Whatsapp groups, two were selected for the study. The two groups selected for the study were those of 300 and 400 levels in the 2017/2018 academic session. The population of the group members at 300 level were 97 while those at 400 level were 103. This gave a total population of 200. Three posts consisting of messages covering information text and supportive images, audio, video and document files posted to the group platform made by three male students and female students in each of the levels in line with the research objectives raised for this study were chosen by expert views for analysis. The reliability of the posts were determined cross checking with the facts on ground to ensure that only


consistent data is used for the analysis. Analysis in this study was done using narratives only. The result of the study shows that Whatsapp groups utilized by undergraduate adult education students in 2017/2018 academic session for the 300 and 400 level students has greatly promoted their learning, social interaction and practice of democracy. The study concluded that the Whatsapp group is a very important platform for undergraduate adult education students. It therefore recommends amongst others, that Class Representatives should partner and add their various course Lecturers to their groups so that they could help them clarify certain concepts or issues they did not understand in the classroom.

Keywords: Adult Learning, Collaborative Learning, Media in Education, Mobile Learning, Social Media

\section{Introduction}

The WhatsApp messenger was purposely created by Brian Acton and Jan Koum in the year 2009. According to the Whatsapp website (2018), WhatsApp is a pun on the phrase What's Up. At the creation of the app, it was tagged "Simple, Personal, Real time messaging". Whatsapp is a mobile messaging app which allows the users to exchange messages without having to pay for SMS. The WhatsApp messenger was purposely created to make communication and the distribution of multimedia messaging more easily and faster. WhatsApp works with internet connectivity and helps its users to stay in touch with friends and relatives in the user's phone contact list. Apart from making its users getting connected with each other, it also helps them to create groups, send unlimited images, video and audio messages. The application is so easy to use after installation. It shows the user all those who are using WhatsApp in your contacts and also helps to invite their friends who are yet to download and use. Then they can start messaging, sharing audio files, video files, updating status, etc. (Jisha, \& Jebakumar, 2014).

According to Olanof, (2012), WhatsApp instant messaging handled ten billion messages per day in August 2012. During June 2013, WhatsApp Inc. announced that they handled 27 billion messages every 24 hours (Sushma, 2012). Parmy, (2013) submitted that WhatsApp had over 450 million monthly active users. Additionally, 700 million photos are shared daily, and 10 billion messages are also shared daily.

Undergraduate adult education students seem to have various communication needs. These communication needs include but not limited to 
communication of when lecture begin/ fixed or will not hold; learning materials are disseminated, when the attention of students are required by authorities, schedule of continuous assessments, examination time table, end of semester results etc. Meeting these communication needs are further worsened by the fact that while some of these undergraduate students are in the hostels in the campus; others are off-campus in scattered locations in the town. This situation is further compounded in times of semester or sessional breaks when the students travel to their various homes which could be scattered around the country and beyond.

It therefore seems not surprising that with the readily available and affordable android mobile phones, it is common to see many of these undergraduate adult education students having android mobile phones in which Whatsapp is installed. Moreover, high speed Internet connections ( $3 \mathrm{G}$ and $4 \mathrm{G}$ ) are now becoming easily accessible and very cheap. Sometimes bonus data is given by some network providers upon airtime top up. This has eventually led to the students forming Whatspp groups. The undergraduate adult education students in the Department of Continuing Education and Extension Services, University of Maiduguri are no exception to this current development. As such, undergraduate adult education students in University of Maiduguri have their class representatives and their assistants as the Whatsapp group administrators who create the groups. The responsibilities of the group administrators include but not limited to adding participants/group members, and removing erring members who constantly violate the ground rules of the rules. This is because ground rules are formed by the class with the consent and approval of their level coordinators. One of the features of the Whatsapp groups by the undergraduate adult education students is the fact that no student can add him/herself. However, a student is free at anytime to exit from the group. Whenever, the student decides to return to the group, he/she would have to be added by any of the group administrator(s). Once, a student is added to the class group he/she can view posts made by any member of the group and can also make posts to the platform for others to see and maybe comment to. Usually, the Level Adviser/Coordinator is added by the administrator to serve as a moderator for the group and monitor what happens in the group.

Studies on the use of different instant messaging platforms has potential to increase learning (Smit, 2012), as such, Bouhnik \& Deshen, (2014); Church $\&$ de Oliveira, (2013); Nguyen \& Fussell, (2016), noted that the application can be a useful tool within the scope of learning anytime anywhere, and for 
collaborative learning. The potentials of Whatsapp on students social interaction, brings Vygotsky, (1978) position of the need to improve social interactions between students and to construct and share knowledge so as to bring about social constructivist learning into reality. Various studies shows the potentials of Whatsapp on students social interaction are: learners' being active in their studies (Cifuentes \& Lents, 2011), interaction between students on personal, school, and course related topics (Cifuentes \& Lents, 2011; Smit, 2012), create sense of belonging (Doering, Lewis, Veletsianos, and NicholsBesel, 2008; Sweeny, 2010), eliminate social barriers (Doering, Lewis, Veletsianos, Nichols-Besel, 2008), and increase students' motivation (Plana et al., 2013).

On the potentials of the Whatsapp in promoting democracy, MacJessieMbewe (1999: 29) earlier submitted that teachers and administrators need to find ways to practise democracy in their own institutions. MacJessie-Mbewe saw the need for teachers and institutions to introduce their students to participation in decision making concerning activities in school. This may be about teaching and activities in the classroom. It may be about deciding on codes of conduct, rules and regulations for the everyday life in the school itself. It is definitely about creating situations where the students are consulted, starting with decisions of limited consequences for the younger students and escalating as the students' maturity develop. Examples may be democratic decision making about fixing a lecture hour that may be convenient for all students.

MacJessie-Mbewe submitted that 'Our students should learn, while still in school, the democratic behaviour of being able to negotiate, by listening to and valuing the views of others, so that they fit easily into the larger democratic society in which they will live after school' (ibid: 25). Therefore it is also an important challenge for schools to motivate students to participate in activities and other democratic procedures for decision making and problem solving. The students should also learn how decisions are made, how to administer a debate in such a way that everybody who is entitled to speak, is allowed to do so and more of that kind.

\section{Statement of the Problem}

The WhatsApp messenger was created in the year 2009 to make communication and the distribution of multimedia messaging more easily and faster. The App works with internet connectivity and helps to create groups, send unlimited images, audio/document files, video and audio messages. 
Undergraduate adult education students seem to have various communication needs for which they could leverage the use of the Whatsapp. It therefore seems not surprising that with the readily available and affordable android mobile phones, it is common to see many of these undergraduate adult education students having android mobile phones in which Whatsapp is installed. Moreover, high speed Internet connections (3G and 4G) are now becoming easily accessible and very cheap. Sometimes bonus data is given by some network providers upon airtime top up. This has eventually led to the students forming Whatspp groups. The undergraduate adult education students in the Department of Continuing Education and Extension Services, University of Maiduguri are no exception to this current development.

Studies available to the researchers show that most of the researches conducted were done on the effects of different instant messaging platforms on students learning and social interaction. See Smit, (2012), Bouhnik and Deshen, (2014); Church and de Oliveira, (2013); Nguyen and Fussell, (2016), Cifuentes and Lents, (2011), Doering, Lewis, Veletsianos, and Nichols-Besel, (2008); Sweeny, (2010), (Plana et al., (2013). Most of these studies on instant messaging platforms are foreign. Some of these studies were conducted using teenagers in Secondary schools as respondents. There is therefore a gap on what could be the potentials of the Whatsapp group platform on Undergraduate students and adult education students in particular. This study therefore investigated the potentials of Whatsapp group in promoting learning, social interaction and democracy among Undergraduate Students in University of Maiduguri, Borno State Nigeria.

\section{Objectives of the Study}

The objectives of this study were to determine the potentials of the Whatsapp group in promoting:

1. learning among Undergraduate Students in University of Maiduguri, Borno State Nigeria.

2. social interaction among Undergraduate Students in University of Maiduguri, Borno State Nigeria.

3. social interaction and democracy among Undergraduate Students in University of Maiduguri, Borno State Nigeria.

\section{Research Questions}

The following questions were answered in this study:

1. What are the potentials of the Whatsapp group in promoting learning among Undergraduate Students in University of Maiduguri, Borno State Nigeria? 
2. What are the potentials of the Whatsapp group in promoting social interaction among Undergraduate Students in University of Maiduguri, Borno State Nigeria?

3. What are the potentials of the Whatsapp group in promoting democracy among Undergraduate Students in University of Maiduguri, Borno State Nigeria?

\section{Scope of the Study}

The study was delimited to Whatsapp groups utilized by undergraduate adult education students in the 2017/2018 academic session. The Whatsapp groups for the current 300 and 400 level students were studied. Three posts consisting of messages covering information text and supportive images, audio, video and document files posted to the group platform made by three male students and female students in each of the levels in line with the research objectives raised for this study were chosen by expert views for analysis. This gave a total of six posts each for the potentials of Whatsapp in promoting learning, social interaction and democracy, respectively making a sum of 18 posts for each level. The variables covered were potentials of Whatsapp in promoting learning, social interaction and democracy; among undergraduate adult education students.

\section{Methodology}

Qualitative design was adopted for the study. This implies that the study was narrative based rather than based on numerical analysis. The population consisted of all the four Whatsapp groups formed for the undergraduate levels of adult education programme. Out of these four Whatsapp groups, two were selected for the study. The two groups selected for the study were those of 300 and 400 levels. This was based on the recognition that the groups had existed for not less than two years. The study was delimited to Whatsapp groups utilized by undergraduate adult education students in the 2017/2018 academic session. The population of the group members at 300 level were 97 while those at 400 level were 103. This gave a total population of 200. Three posts consisting of messages covering information text and supportive images, audio, video and document files posted to the group platform made by three male students and female students in each of the levels in line with the research objectives raised for this study were chosen by expert views for analysis.

Bailey (1994) acknowledges that documentary analysis helps us analyse documents that contain information about the phenomenon we wish to investigate. The validity of the items needed in the posts were determined by 
experts in Social Media and Information and Communications Technology, University of Maiduguri. The reliability of the posts were determined cross checking with the facts on ground to ensure that only consistent data is used for the analysis. In order to be able to access the posts in the groups, the researchers explained the purpose of the study to the group administrators; and sought the permission of the class representatives who are the group administrators to add them as participants into the groups. This enabled the researchers to view and analyse the posts made by students in the groups. Analysis in this study was done using narratives only.

\section{Results and Discussion}

Research Question 1: What are the potentials of the Whatsapp group in promoting learning among Undergraduate Students in University of Maiduguri, Borno State Nigeria?

\section{Response to Research Question 1:}

Based on messages covering information text and supportive images, audio, video and document files posted to the group platform made by undergraduate adult education students in each of the levels in line with this research objective raised as chosen by expert views, shows that posts relating to University calendar of events, lecture notes, Departmental course allocation to Lecturers, lecture and examinations time tables, tips on effective study habits, information about lectures, stories with moral lessons, videos demonstrating how things are done, inspirational images such as that of a man who stated that "FAIL" means First Attempt In Learning", hence students should not fear failing; distribution of students into group assignments, information on deadlines to submit assignments and how, information on where lectures are going on for students who are not already in class or not sure of the lecture venue were made on the group chat. These were highly relevant in informing the students to be abreast of happenings related to their learning and subsequent graduation from the programme.

Research Question 2: What are the potentials of the Whatsapp group in promoting social interaction among Undergraduate Students in University of Maiduguri, Borno State Nigeria?

\section{Response to Research Question 2:}

Text and supportive images, audio, video and document files posted to the group platform made by undergraduate adult education students in each of the levels in line with this research objective raised as chosen by expert views, shows that messages asking group members about how they are faring, 
sympathizing with members of the class in the case of the loss of a loved class member, wishing the class members a happy celebration during festive periods, inviting class members to events such as marriages, naming ceremonies and burials, sometimes when a discussion comes up about a student who is not well known his/her picture is posted to the platform so that others could see and know him/her. The platform also provides an avenue to have the contacts or phone numbers of the group member's classmates which could be viewed from the Group info menu. This goes a long way in helping students in a class know each other, have empathy for one another, celebrate events and promote unity among the students which is one of the missing ingredients in our country today.

Research Question 3: What are the potentials of the Whatsapp group in promoting democracy among Undergraduate Students in University of Maiduguri, Borno State Nigeria?

Response to Research Question 3:

The operation of the Whatsapp group platform among undergraduate adult education students in the University of Maiduguri has it that class representatives and their assistants are the Whatsapp group administrators who create the groups. The responsibilities of the group administrators include but not limited to adding participants/group members, and removing erring members who constantly violate the ground rules of the rules. This is because ground rules are formed by the class with the consent and approval of their level coordinators. One of the features of the Whatsapp groups by the undergraduate adult education students is the fact that no student can add him/herself. However, a student is free at anytime to exit from the group. Whenever, the student decides to return to the group, he/she would have to be added by any of the group administrator(s). Once, a student is added to the class group he/she can view posts made by any member of the group and can also make posts to the platform for others to see and maybe comment to. Usually, the Level Adviser/Coordinator is added by the administrator to serve as a moderator for the group and monitor what happens in the group. This provides an avenue for students to participate in what affects them directly or indirectly in their learning and consciously or unconsciously participate in democracy.

\section{Conclusion}

This study investigated the potentials of Whatsapp group in promoting learning, social interaction and democracy among Undergraduate Students in University of Maiduguri, Borno State Nigeria. Based on posts consisting of messages 
covering information text and supportive images, audio, video and document files posted to the group platform made by three male students and female students in each of the levels in line with the research objectives raised for this study were chosen by expert views for analysis; it could be said that Whatsapp groups utilized by undergraduate adult education students between 2017/2018 academic session to date for the current 300 and 400 level students has proven to be a very important platform for undergraduate adult education students.

\section{Recommendations}

Based on the findings from this study, the following recommendations were made:

1. Class Representatives should partner and add their various course Lecturers to their groups so that they could help them clarify certain concepts or issues they did not understand in the classroom.

2. Student Advisers and the Head of Department as well as the Dean and Faculty Officers should be added to the Whatsapp groups to boost the social interaction on the platform.

3. Undergraduate adult education students should give awards to the five most participating students on the Whatsapp group during their graduation celebrations.

\section{References}

Bailey, K. (1994). Methods of Social Research. (Fourth Edition), New York: The Free Press.

Bouhnik, D., \& Deshen, M. (2014). WhatsApp goes to school: Mobile instant messaging between teachers and students. Journal of Information Technology Education: Research, 13, 217-231. Retrieved from http://www.jite.org/documents/Vol13/JITEv13ResearchP217231Bouhnik0601.pdf

Church, K., \& de Oliveira, R. (2013). What's up with WhatsApp? Comparing mobile instant messaging be-haviors with traditional SMS. Proceedings of the 15th International Conference on Human-computer Interaction with Mobile Devices and Services (pp. 352-361). New York, USA: ACM. doi: $10.1145 / 2493190.2493225$ 
Cifuentes, O. E., \& Lents, N. H. (2011). Increasing student-teacher interactions at an urban commuter campus through instant messaging and online office hours. Electronic Journal of Science Education, 14(1), 1-13. Retrieved from http://ejse.southwestern.edu/article/view/7314

Doering, A., Lewis, C., Veletsianos, G., \& Nichols-Besel, K. (2008). Preservice teachers' perceptions of instant messaging in two educational contexts. Journal of Computing in Teacher Education, 25(1), 5-12. Retrieved from http://files.eric.ed.gov/fulltext/EJ834086.pdf

Jisha, K., \& Jebak, U. (2014). Whatsapp: A Trend Setter in Mobile Communication among Chennai Youth. IOSR Journal of Humanities and Social Science 19, (9).

Nguyen, D. T., \& Fussell, S. R. (2016). Effects of conversational involvement cues on understanding and emotions in instant messaging conversations. Journal of Language \& Social Psychology, 35(1), 28-55. doi: $10.1177 / 0261927 \mathrm{X} 15571538$

Olanof, D. (2012). WhatsApp hits new record with 10 billion total messages in one day. The Next Web.

Parmy O. (2013). Teenagers say goodbye to Facebook and hello to messenger apps. The Guardian.

Plana, M. G- C., Escofet, M. I. G., Figueras, I. T., Gimeno, A., Appel, C., \& Hopkins, J. (2013, July). Improving learners' reading skills through instant short messages: A sample study using WhatsApp. 4th WorldCALL Conference, Glasgow. Retrieved from https://www.researchgate.net/publication/255718202_Improving_learners '_reading_skills_through_instant_

Smit, I. (2012). WhatsApp with BlackBerry; Can messengers (BBM) be MXit? In Proceedings of the 14th annual conference on world wide web applications. Cape Town, South Africa: Cape Peninsula University of Technology. Retrieved from http://hdl.handle.net/10394/13628 
Sushma, P. (2012). WhatsApp founder to operators: We're no SMSkiller, we get people hooked on data. The Next Web.

Sweeny, S. M. (2010). Writing for the instant messaging and text messaging generation: Using new litera-cies to support writing instruction. Journal of Adolescent \& Adult Literacy, 54(2), 121-130. doi: 10.1598/JAAL.54.2.4

Vygotsky, L.S. (1978). Mind in society: The development of higher psychological processes. Cambridge. MA: Havard University Press.

Whatsapp Website (2018). About WhatsApp. Downloaded 20/11/2018. Retrieved from https://www.whatsapp.com/about/ 